\title{
Old problem new approach- malposition of tracheostomy tube in patient with anatomical deformity
}

\author{
Vanita Ahuja $^{1 *}$, Deepak Thapa ${ }^{2}$, Dheeraj Kapoor ${ }^{1}$, Navneet Kumar ${ }^{3}$, Ravinder Kaur ${ }^{2}$ \\ Assistant Professor ${ }^{1}$, Associate Professor ${ }^{2}$, Postgraduate student ${ }^{3}$, Department of Anaesthesia and \\ Intensive care, Government Medical College and Hospital Sector 32, Chandigarh, India.
}

\section{*Corresponding author: vanitaanupam@yahoo.co.in}

\begin{abstract}
The size of the tracheostomy tube (TT) in relation to the airway should be guided by the underlying anatomical deformity. The optimal choices in tracheostomy tube selection in such patients are not defined. This case report describes some discernible issues involved in the management of a patient with restrictive lung disease due to severe kypho-scoliosis with type II respiratory failure admitted in the ICU of our institution. Computed tomography (CT) scan was instrumental in measuring the infragottic length and diameter of trachea. This expedited the weaning process of patient and her discharge from ICU.
\end{abstract}

Keywords: tracheostomy tube; anatomical deformity; computed tomography

\section{Introduction}

A patient spends as much as $42 \%$ of the time during weaning from mechanical ventilation with a likely higher percentage in patients with lung disease. ${ }^{1}$ Malpositioning of tracheostomy tubes (TT) occurs in $10 \%$ of intensive care unit (ICU) patients. $^{2}$ Early tracheostomy can significantly hasten the process of weaning from mechanical ventilation but issues regarding TT needs to be considered. ${ }^{2}$

\section{Case report}

A 32 year old female patient was admitted in the ICU with severe restrictive lung disease and kypho-scoliosis involving thoracic vertebrae (T4T11). She had dyspnoea on exertion since last ten days which worsened to type II respiratory failure. On admission, the patient's Glasgow coma scale (GCS) was 8 (E3V1M4) with a pulse rate of $120 / \mathrm{min}$ and non invasive blood pressure of $70 / 50 \mathrm{mmHg}$. On auscultation of lung, bilateral rhonchi were present. Her arterial blood gas (ABG) analysis showed uncompensated metabolic and respiratory acidosis. Trachea was intubated with $7.0 \mathrm{~mm}$ ID endotracheal tube and respiration was supported with synchronized intermittent mandatory ventilation (SIMV) (frequency-16/min, tidal volume $-180 \mathrm{ml}$, peak inspiratory pressure $23 \mathrm{~cm} \mathrm{H}_{2} \mathrm{O}$, positive end expiratory pressure $-5 \mathrm{~cm}$ $\mathrm{H}_{2} \mathrm{O}$ ). Supportive ICU treatment was started . Her routine laboratory blood investigations were normal. Chest X-ray showed severe thoracic scoliosis with crowding of ribs on left side of chest and left hypoplastic lung. On the fifth day, surgical tracheostomy was done and a $7.0 \mathrm{~mm}$ ID TT (cuffed blue line ultra, Portex ${ }^{\circledR}$ ) was inserted in anticipation of prolonged ventilatory support. Following tracheostomy, patient had decreased air entry on left side of the chest, $\mathrm{SpO}_{2}$ decreased to $80 \%$ with static compliance of $15 \mathrm{ml} / \mathrm{cm} \mathrm{H}_{2} \mathrm{O}$ and resistance of $30 \mathrm{~cm}$. Ultrasonography (USG) and X ray chest ruled out the possibility of pneumothrax. On fiberoptic bronchoscopy the TT was endobronchial in right principle bronchus and its distal end was abutting the mucosa. We immediately pulled out the tube by approximately $2 \mathrm{~cm}$ and secured its new position by applying cotton padding under the flange of the tube, as the TT with adjustable flange was not available. Ventilation was supported but patient still had hypoxemia and hypercarbia on blood gas analysis. Thereafter computed tomography (CT) scan of the chest was done which showed severe kyphoscoliosis (T4-T11), left lung collapse with mediastinal shift, minimal pleural effusion, and calcific lesions in left collapsed lung (Figure-1).

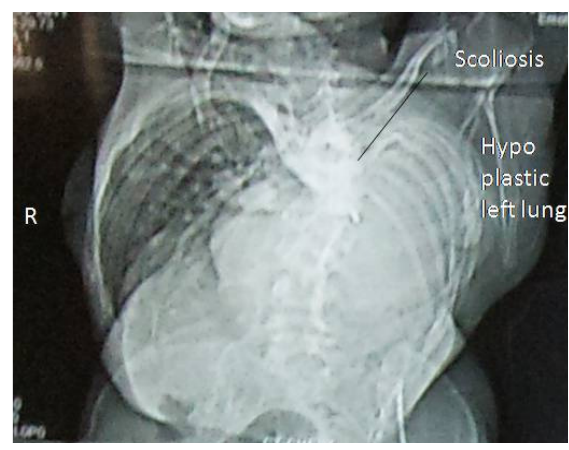


The tracheal length was of $8.00 \mathrm{~cm}$ with variable diameter of $10 \mathrm{~mm}$ infraglottic to $6 \mathrm{~mm}$ at the level of TT and the distance from the tip of TT to carina was $1.5 \mathrm{~cm}$. We eventually planned to insert a TT of $6.0 \mathrm{~mm}$ ID. Subsequent flexible fiberoptic bronchoscopy confirmed correct placement of TT. Patient received weaning trials over a period for next four weeks and her trachea was decannulated after three months of ICU stay.

\section{Discussion}

Patients with severe kyphoscoliosis are difficult to manage in ICU due to compensatory changes that occur in these patients. Hypoxemia and secondary hypercapnia occurs rapidly with haemodynamic instability. These patients adopt low tidal volume, high respiratory rate which increases the ventilator work. $^{3}$

Ideally TT must fit the airway without causing any undue pressure on any portion of the neck or trachea and should fulfil the functional needs of the patient. The OD of a TT needs to be no more than the two-thirds to three-quarters of internal diameter of trachea as a bigger tube impedes air flow when the cuff is deflated and a smaller tube can increase pressure on surrounding mucosa after cuff inflation. ${ }^{4}$ A $10 \mathrm{~mm}$ outer diameter (OD ) and $7.00 \mathrm{~mm}$ ID TT for adult women is usually appropriate as an initial size. ${ }^{5}$

Other better options in this patient would have been a silicon tube which easily fits to the contour of airway and TT with adjustable flange.

The correct placement of TT warrants tip of the TT to be halfway between stoma and carina, should be $2 / 3$ rd of the width of trachea diameter and cuff should not cause any bulge on the tracheal wall. ${ }^{6}$ Tracheal anatomic length in adults is 10.5 to $13 \mathrm{~cm}$ with height of 1.50 to $1.80 \mathrm{~m}^{7}$ Patients with a shorter height are at increased risk of malposition. ${ }^{7}$ Hence, TT $6.00 \mathrm{~mm}$ ID with an OD of $8.5 \mathrm{~mm}$, an angle of $90-105^{\circ}$ and length of $64 \mathrm{~mm}$ was beneficial for the patient.

Computed tomography scans aids to determine estimation of tracheal diameter, cross-sectional area, volume and length in vivo and can be an invaluable asset in size estimations of tracheostomy tubes for the intensivist. ${ }^{7}$
To conclude, an individualized approach for TT size is required in these patients to expedite patient's liberation from ventilator and discharge from ICU.

\section{References}

1. Esteban A, Alia I, Ibanez J, Benito S, Tobin MJ. Modes of mechanical ventilation and weaning: A national survey of Spanish hospitals; The Spanish Lung Failure Collaborative Group. Chest 1994;

106:1188-93

http://dx.doi.org/10.1378/chest.106.4.1188

PMid:7924494

2. Schmidt U, Hess D, Kwo J, Lagambina S, Gettings E, Khandwala F, Bigatello LM et al. Following Prolonged Ventilation Admitted to a Respiratory Acute Care Unit Tracheostomy. Chest 2008; 134; 288-94 http://dx.doi.org/10.1378/chest.07-3011 PMid:18403659

3. Brack T, Jubran A, Tobin MJ. Dyspnea and Decreased Variability of Breathing in Patients with Restrictive Lung Disease. Am J Respir Crit Care Med 2002; 165:1260-4 http://dx.doi.org/10.1164/rccm.2201018

PMid:11991875

4. MacIntyre NR. Evidence-Based Guidelines for Weaning and Discontinuing Ventilatory Support : A collective Task Force facilitated by the American College of Chest Physicians; The American Association for Respiratory Care; and the American College of Critical Care Medicine. Chest 2001;120:375S-396S

http://dx.doi.org/10.1378/chest.120.6_suppl.375S PMid:11742959

5. Hess DR. Tracheostomy tubes and related appliances. Respir Care 2005;50:497-510 PMid:15807912

6. Raby N, Berman L, de Lacey G. Accident \& Emergency Radiology: a survival guide. 2nd ed. Philadelphia: Elsevier Saunders, 2005

7. Griscom NT, Wohl MEB. Dimensions of the growing trachea related to body height. Length, anteroposterior and transverse diameters, crosssectional area, and volume in subjects younger than 20 years of age. Am Rev Respir Dis 1985;131: 840-4 PMid:4003934 